\title{
Staphylococcal Esophagitis Causing Giant Ulcers
}

\author{
J. Thomas Miller, Jr., Shawn W. Slywka, and James H. Ellis \\ Department of Radiology, University of Michigan Medical Center, Ann Arbor, Michigan, USA
}

\begin{abstract}
A 29-year-old woman with Hodgkin disease developed odynophagia while receiving chemotherapy. Large esophageal ulcers due to staphylococcal infection of the mucosa were visualized by endoscopy and radiography. This unusual bacterial esophagitis represents another potential cause of giant esophageal ulcerations.
\end{abstract}

Key words: Esophagitis, bacterial-Esophageal ulcer, diagnosis.

Infectious esophagitis is a common complication in immunocompromised patients; it is usually caused by Candida albicans, herpes simplex virus, cytomegalovirus (CMV), or human immunodeficiency virus (HIV) [1-5]. We report an unusual case of bacterial esophagitis with giant mucosal ulcerations similar to those previously described for CMV and HIV infection.

\section{Case Report}

A 29-year-old woman diagnosed with stage IIIB nodular sclerosing Hodgkin lymphoma presented to our institution for autologous bone marrow transplantation after the malignancy proved refractory to extensive radiation and chemotherapy. At the time of admission her physical exam was unremarkable-including no evidence of lesions, ulcers, or exudates in the oropharynx. Her white blood cell count and differential were normal.

After 4 days of combination chemotherapy in preparation for peripheral stem cell and bone marrow infusion, she began to experience severe dysphagia and odynophagia. A decrease in her white blood cell count was accompanied by episodic spiking fevers. She was found to have a slightly erythematous pharyngeal mucosa but laryngoscopy revealed no lesions. Multiple oropharyngeal and blood fungal cultures showed no growth. The patient remained symptomatic despite intravenous fluconazole, intravenous eryth-

Address offprint requests to: Tom Miller, Jr., M.D., Department of Radiology, University of Michigan Medical Center, $1500 \mathrm{E}$. Medical Center Drive, Ann Arbor, MI 48109-0030, USA romycin, and oral nystatin therapy. Endoscopy revealed extensive confluent ulcerations of the esophagus with exudation, hemorrhage, and small mucosal tears. Cytologic brushings revealed an inflammatory process with clusters of Staphylococcus species and polymorphic neutrophils filled with Gram-positive cocci. Her cytomegalovirus and herpes simplex antibody titers were elevated, but the cytological specimens did not reveal any mycelia or intranuclear inclusions and multiple cultures were negative for viral growth.

A single-contrast esophagram was performed about $2 \mathrm{~h}$ later to evaluate the tears seen at endoscopy. No transmural leaks were found, but there was a gross irregularity of the mucosal pattern throughout the entire esophagus. Several large elongated ulcers surrounded by a thin radiolucent rim were noted in the mid- and distal esophagus (Fig. 1). Mobility throughout the esophagus was normal.

The patient was started on intravenous vancomycin. There was a slight improvement in symptoms. Four days after the endoscopy and esophagram, the patient regurgitated a large piece of tissue-like material which was microscopically identified as squamous epithelial cells and fibrinous clot, apparently sloughed from the esophageal mucosa. Large colonies of staphylococci were identified, but there was no evidence of viral or fungal infection. One day later, following the expulsion of a similar specimen of material, a repeat esophagram revealed a loss of the distinct ulcer pattern with a significant loss of normal motility.

While the esophageal symptoms continued to decrease over the next 2 weeks, the patient died of multisystem organ failure and an overwhelming monilial sepsis. At autopsy there was no evidence of esophageal ulceration and its muscular wall was intact.

\section{Discussion}

Opportunistic infections are quite common in immunocompromised patients and are responsible for much of the associated morbidity and mortality. The esophagus is a common site for these infections. The clinical picture is one of acute odynophagia, dysphagia, and substernal pain or burning [1-3]. Candida albicans, herpes simplex virus I, and cytomegalovirus are the most commonly encountered pathogens in these patients [1-4]. However, various bacteria have also been recognized as the primary cause of infection in immunodeficient patients $[3-4,6-8]$. The actual incidence of primary bacterial infections is not 


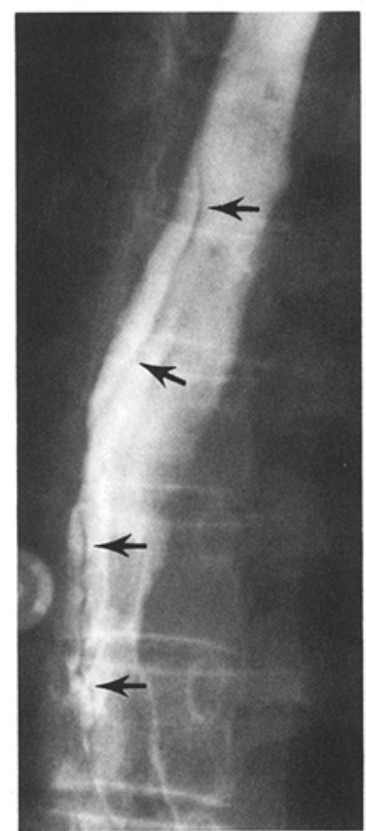

Fig. 1. Esophagram shows several large and elongated ulcers that are outlined by a radiolucent border (arrows).

known, but a recent study reported an autopsy rate of $16 \%$ and a biopsy rate of $11 \%$ in immunocompromised or debilitated patients [4]. McDonald et al. reported similar findings at autopsy for patients having received bone marrow transplantation [3].

To our knowledge the radiographic findings in staphylococcal esophagitis have not been reported. The initial radiographs showed several large, longitudinal collections of barium extending beyond the mucosal borders in the mid- and distal esophagus. Each was outlined with a radiolucent margin (Fig. 1). Based on the endoscopic findings of the same day, these most likely represented areas of extensive necrosis, ulceration, and edema. Following the sloughing of the necrotic material the ulcer pattern disappeared, leaving an irregular but nonspecific mucosal pattern. From the autopsy finding, we presumed there was adequate response to intravenous antibiotics and the mucosa had healed in the 3-week interval between the original esophagram and death.

The quality of our original examination was lim- ited because we were actually looking for perforation and felt compelled to use aqueous contrast material. Nonetheless, the findings were quite similar to previously described cases of CMV [1,9] and giant HIV ulcers in the mid- and distal esophagus [5].

There are several noninfectious causes of giant esophageal ulcers. Consideration should be given to these even if the patient is immunocompromised. Levine et al. [10], recently added Clinoril (a nonsteroidal antiinflammatory drug) to the list of differential diagnoses which already included quinidine, nasogastric intubation, Crohn disease, Behçet syndrome, and ulcerative carcinomas. The similarity of the radiographic features in our patient with staphylococcal esophagitis to those reported in some fungal and viral infections suggest that giant ulcers are not specific. The actual causative agent must be identified by biopsy and/or culture.

\section{References}

1. Balthazar EJ, Megibow AJ, Hulnick D, Cho KC, Berenbaum E. Cytomegalovirus esophagitis in AIDS: radiographic features in 16 patients. AJR 1987;149:919-923

2. Levine MS, Laufer I, Kressel HY, Friedman HM. Herpes esophagitis. AJR 1981;136:863-866

3. McDonald GB, Sharma P, Hackman RC, Meyers JD, Thomas ED. Esophageal infections in immunosuppressed patients after marrow transplantation. Gastroenterology 1985;88:1111-1117

4. Walsh TJ, Belitsos NJ, Hamilton SR. Bacterial esophagitis in immunocompromised patients. Arch Intern Med 1986;146: $1345-1348$

5. Levine MS, Loercher G, Katzka DA, Herlinger H, Rubesin SE, Laufer I. Giant human immunodeficiency virus-related ulcers in the esophagus. Radiology 1991;180:323-326

6. Athey PA, Goldstein HM, Dodd GD. Radiologic spectrum of opportunistic infections of the upper gastrointestinal tract. AJR 1977;129:419-424

7. Dow, CJ. Oesophageal tuberculosis: four cases. Gut 1981;22:234-236

8. Ezzell JH, Bremer J, Adamec TA. Bacterial esophagitis: an often forgotten cause of odynophagia. Am J Gastroenterol 1990;85:296-298

9. St. Onge G, Bezahler GH. Giant esophageal ulcer associated with cytomegalovirus. Gastroenterology 1982;83:127-130

10. Levine MS, Rothstein RD, Laufer I. Giant esophageal ulcer due to clinoril. AJR 1991;156:955-956

Received: June 26, 1992; accepted: August 6, 1992 